Бычков А. В.

\begin{abstract}
Аннотация. Цель исследования - выяснить содержание математической грамотности учащихся для определения содержательных основ методической подготовки будущего учителя математики. В статье рассмотрено понятие математической грамотности в контексте формирования функциональной грамотности учащихся основной школы. Проведен анализ структуры математической грамотности и исследований, посвященных вопросам формирования содержания отдельных ее компонентов. Показано, что в отечественных исследованиях не сложилось единого подхода к определению набора действий, которым необходимо обучать школьников при выполнении ими этапа формализации ситуации, представленной на естественном языке, и интерпретации полученного результата при решении практико-ориентированных задач. На основе анализа инструментария международного исследования PISA и работ отечественных исследователей составлен перечень действий, целенаправленное обучение которым позволит подготовить будущего учителя математики к формированию у учащихся умений по построению математической модели и интерпретации полученных результатов в процессе решения практико-ориентированных задач. Научная новизна исследования заключается в обосновании необходимости включения в содержание методической подготовки будущего учителя математики специальных действий, лежащих в основе этапов формализации ситуации, представленной на естественном языке, и интерпретации полученных результатов в ходе решения практико-ориентированных задач, с целью формирования математической грамотности учащихся. В результате показана связь между некоторыми специфическими действиями, необходимыми для осуществления этапа формализации ситуации, представленной на естественном языке, и коммуникативными, учебными и информационными умениями, определяющими функциональную грамотность учащихся основной школы.
\end{abstract}

\title{
Substantive Foundations of Future Mathematics Teachers' Training for Mathematical Literacy Formation in Primary School Students
}

\section{Bychkov A. V.}

\begin{abstract}
The study aims to identify the content of students' mathematical literacy in order to determine the substantive foundations of future mathematics teachers' methodological training. The paper considers the notion of mathematical literacy in the context of functional literacy formation in primary school students. The author analyses the structure of mathematical literacy and research papers addressing the formation of the content of its individual components. The work shows that in Russian studies, there is no unified approach to determining the set of actions that need to be taught to schoolchildren when they operate at the stage of formalisation of a situation presented in a natural language and interpretation of the result obtained in the process of solving practice-oriented tasks. Having analysed the toolkit of the international PISA study and papers by Russian researchers, the author has compiled a list of actions targeted training of which will prepare future mathematics teachers for the formation of students' skills in building a mathematical model and interpreting the results obtained in the process of solving practice-oriented tasks. Scientific novelty of the study lies in providing rationale for the need to include in the content of future mathematics teachers' methodological training special actions underlying the stages of formalisation of a situation presented in a natural language and interpretation of the results obtained in the course of solving practice-oriented tasks with the purpose of forming students' mathematical literacy. As a result, the relationship between certain specific actions necessary for the implementation of the stage of formalisation of a situation presented in a natural language and communicative, educational and informational skills that determine primary school students' functional literacy has been shown.
\end{abstract}




\section{Введение}

В настоящее время перед школой остро стоит проблема формирования личности, способной действовать в условиях неопределенности и быстро адаптирующейся к изменяющимся условиям мира. Однако опыт участия российских школьников в международных исследованиях (Краткие результаты..., 2019) и анализ такого опыта специалистами Института стратегии развития образования Российской академии образования (ИСРО РАО) (Ковалева, Красновский, Краснокутская и др., 2004) убедительно доказывают, что российское образование, в частности математическое, в большей степени нацелено на овладение предметными умениями и навыками и в меньшей степени - на сформированность умений, которые могут пригодиться в жизни, т.е. функциональной грамотности.

О. К. Подлипский (2020, с. 104-106) отмечает, что на сегодняшний день существует проблема внедрения в систему российского математического образования одного из видов функциональной грамотности - математической. Данная проблема проявляется, во-первых, в недостаточной проработанности вопроса, связанного с методикой, которая бы позволяла органично включить содержание математической грамотности в содержание математической подготовки учащегося, не разрушая при этом ее фундаментальности. Во-вторых, в настоящее время не до конца решена проблема конструирования заданий, направленных на формирование математической грамотности. О существовании данных проблем свидетельствует и исследование, проведенное Л. О. Рословой и И. И. Карамовой (2020, с. 25). Согласно этому исследованию, 42\% опрошенных учителей отмечают, что главной проблемой при формировании математической грамотности является отсутствие методического обеспечения (заданий, методик формирования, дидактических материалов, средств контроля). Наконец, в-третьих, потребуется методическая подготовка учителей, способных системно выстроить работу по формированию математической грамотности у учащихся основной школы. Отмечая, что учитель математики должен уметь делать то, чему ему предстоит научить школьников, важно выяснить содержание математической грамотности учащихся основной школы для определения содержательных основ методической подготовки будущего учителя математики. Этим и обосновывается актуальность разработки темы нашего исследования.

Для достижения поставленной цели необходимо решить следующие задачи:

- рассмотреть понятие математической грамотности и ее структуру в контексте формирования функциональной грамотности учащихся основной школы;

- выделить перечень специальных действий, которыми необходимо овладеть будущему учителю математики для формирования у учащихся основной школы умений строить математические модели и интерпретировать полученные результаты в процессе решения практико-ориентированных задач.

В соответствии с поставленными задачами исследования использовались следующие методы исследования: теоретический анализ отечественной научной и научно-методической литературы, диагностического инструментария международного исследования PISA.

Практическая значимость исследования заключается в том, что выявленный набор действий, необходимых для осуществления этапов формализации ситуации, представленной на естественном языке, и интерпретации полученных результатов при решении практико-ориентированных задач, позволит разработать и внедрить в процесс методической подготовки будущего учителя математики методику формирования математической грамотности учащихся основной школы.

\section{Понятие математической грамотности и ее структура в контексте формирования функциональной грамотности учащихся основной школы}

Международное исследование оценки качества образования PISA посвящено изучению вопроса: «Обладают ли учащиеся 15-летнего возраста, получившие обязательное общее образование, знаниями и умениями, необходимыми им для полноценного функционирования в современном обществе?» (PISA 2018..., 2019). Содержание, вкладываемое разработчиками PISA в цель данного исследования, сводится к понятию «функциональная грамотность», которое А. А. Леонтьев раскрывает через понятие функционально грамотной личности: «Функционально грамотная личность - это личность, которая способна использовать все постоянно приобретаемые в течение жизни знания, умения и навыки для решения максимально широкого диапазона жизненных задач в различных сферах человеческой деятельности, общения и социальных отношений» (Образовательная система..., 2003, с. 35).

Член-корреспондент РАО Н. Ф. Виноградова и соавторы (Виноградова, Кочурова, Кузнецова, 2018) отмечают, что владение функциональной грамотностью означает:

- готовность успешно взаимодействовать с изменяющимся окружающим миром;

- возможность решать различные (в том числе нестандартные) учебные и жизненные задачи;

- способность строить социальные отношения;

- совокупность рефлексивных умений, обеспечивающих оценку своей грамотности, стремление к дальнейшему образованию.

В рамках своей научно-исследовательской деятельности для характеристики функциональной грамотности коллектив ИСРО РАО наряду с предметными компонентами, которые связаны с содержанием изучаемых 
школьниками предметов, предлагает выделять интегративные компоненты, т.е. такие, которые отражают метапредметные результаты обучения (Дидактическое сопровождение..., 2017).

В качестве таких интегративных компонентов А. Б. Воронцов (2013) выделяет следующие виды грамотностей, в каждой из которых рассматриваются определенные группы умений:

- Учебная грамотность. Выделяются группы умений, связанные с организацией своей деятельности и умением учиться.

- Информационная грамотность. Выделяются группы умений, связанные с получением информации и созданием, представлением и передачей сообщения.

- Коммуникативная грамотность. Выделяются группы умений, связанные с непосредственным взаимодействием с другими людьми и взаимодействием, опосредствованным письменными текстами.

Перечень самих умений, входящих в каждую из указанных выше групп, можно найти, например, в статье А. Б. Воронцова (2013) про метапредметные образовательные умения.

В то же время в рамках исследования PISA предложены следующие виды функциональной грамотности:

1) читательская;

2) математическая;

3) естественнонаучная;

4) финансовая;

5) глобальные компетенции.

Остановимся далее подробнее на рассмотрении математической грамотности с целью определить, чем конкретно должен овладеть учащийся основной школы, чтобы быть математически грамотным, а также выяснить, как содержание математической грамотности может помочь в формировании учебных, информационных и коммуникативных умений, предложенных А. Б. Воронцовым.

В материалах международного исследования PISA под математической грамотностью понимают «способность индивидуума проводить математические рассуждения и формулировать, применять, интерпретировать математику для решения проблем в разнообразных контекстах реального мира» (OECD Governing Board..., 2018, c. 8). Как видно из предложенного определения, во-первых, понятие «математическая грамотность» дается через понятие «способность». Рассуждая о проблеме определения понятия «способность», Б. М. Теплов (2018) говорит, что под способностями понимаются не врожденные возможности человека, а его индивидуально-психологические особенности. Кроме того, отмечается, что способность существует в развитии. А поскольку развитие возможно только в процессе осуществления некоторой деятельности, то и способность не может возникнуть вне данной деятельности. Во-вторых, эта способность связана с овладением методом математического моделирования, который включает в себя выполнение трех этапов: построение математической модели, применение математического аппарата к этой модели и интерпретацию полученного результата.

Учитывая определение математической грамотности, приведенное в исследовании PISA, а также трактовку понятия «способность», которую дает Б. М. Теплов, уточним определение математической грамотности: математическая грамотность - это индивидуально-психологическая особенность человека, которая возникает в процессе деятельности, направленной на построение математической модели, применение математического аппарата к этой модели, интерпретацию полученного результата, и влияет на дальнейшую успешность осуществления такой деятельности.

Таким образом, для того чтобы учащийся основной школы стал математически грамотным, потребуется, чтобы он приобрел опыт в деятельности, направленной на осуществление этапов математического моделирования. Чтобы проследить, что же должен включать в себя опыт этой деятельности, обратимся к статье Т. А. Ивановой и О. В. Симоновой (2009), в которой проанализирована структура математической грамотности и предлагаются следующие ее компоненты:

1. Информационный. Данный компонент предполагает владение определенной математической информацией (формулировками определений, теорем, алгоритмов).

2. Логический. В процессе математической деятельности учащиеся должны овладеть логическими действиями.

3. Методологический. Этот компонент подразумевает овладение дедуктивными, эвристическими методами и приемами математической деятельности, в том числе методами доказательств.

4. Практический. Учащиеся должны освоить элементы метода математического моделирования. В данном случае важно, чтобы школьники не только познакомились с информацией о сути этого метода, но и овладели всеми тремя этапами, благодаря которым возможно применять данный метод: построение математической модели, применение математического аппарата к этой модели, интерпретация полученного результата.

Как отмечают сами исследователи, предлагаемая ими структура математической грамотности является общей и, безусловно, для ее формирования у школьников необходимо определить более конкретные ориентиры. Поэтому исследуем проработанность вопроса о содержании каждого из заявленных компонентов в методике обучения математике.

Как видно из структуры математической грамотности, для того чтобы у учащегося сформировать данный вид грамотности, его математическая подготовка должна быть направлена на овладение содержанием информационного, логического и методологического компонентов. Это, в свою очередь, позволит учащимся успешно применять математический аппарат к построенной модели при условии, что этап формализации ситуации, представленной на естественном языке, до этого за них кто-то осуществит. 
Заметим, что в теории и методике обучения математике накоплен огромный опыт по овладению учащимися содержанием названных компонентов. В качестве наиболее значимых среди таких исследований следует выделить работы Г. И. Саранцева (2002) и Т. А. Ивановой (2009), в которых представлена технология обучения основным дидактическим единицам и адекватным им действиям. Кроме того, в методике обучения математике имеется достаточное количество публикаций, подтверждающих, что с помощью предметного содержания курса математики возможно формировать группы умений, представленных в работе А. Б. Воронцова (2013). В этом отношении наиболее важными для нас являются труды Л. И. Боженковой (2017; 2020), Е. Е. Алексеевой (2017), С. П. Беребердиной (2018). В работах указанных авторов раскрываются теоретические и практические аспекты формирования универсальных учебных действий, входящих в состав групп умений, заявленных А. Б. Воронцовым. Выскажем также важное замечание о том, что для формирования коммуникативных умений учащихся следует учитывать не только содержание изучаемого материала, но и формы совместной с учащимися деятельности, которые использует учитель.

Безусловно, эти выводы подтверждают тезис о том, что осваиваемые действия внутри математической деятельности направлены на достижение метапредметных результатов обучения, которые отражают интегративные компоненты функциональной грамотности.

Однако невысокие результаты участия российских учащихся в международном исследовании PISA (Kраткие результаты..., 2019) показывают, что только действий, приобретаемых на предметном материале математики, для овладения математической грамотностью, очевидно, недостаточно. Анализ школьных учебников по математике и диссертационных исследований (Былков, 1986; Бобровская, 1996; Иванова, 1998; Егупова, 2014) позволил выявить существующю проблему, связанную с освоением школьниками содержания практического компонента математической грамотности, включающего в себя учебные действия на этапах формализации ситуации, представленной на естественном языке, и интерпретации полученных результатов. Поэтому выделим далее группы действий, которыми потребуется овладеть будущему учителю математики для формирования у учащихся умений по построению математических моделей и интерпретации полученных результатов в ходе решения практико-ориентированных задач.

\section{Специальные действия, которыми необходимо овладеть будущему учителю математики для формирования у учащихся основной школы умений строить математические модели и интерпретировать полученные результаты}

Анализ работ отечественных исследователей по проблеме внедрения метода математического моделирования в процесс обучения математике в основной школе (Егупова, 2014; Бобровская, 1996; Стукалов, 1975; Былков, 1986; Шапиро, 1990; Малкова, Монахов, 1984), а также инструментария международного исследования PISA (PISA 2021..., 2018), показал, что в настоящее время не сложилось единого подхода к определению набора действий, лежащих в основе выполнения этапа формализации ситуации, представленной на естественном языке. Сопоставление и обобщение действий, имеющихся в названных исследованиях, позволили выделить действия, необходимые для построения математической модели, и представить их в Таблице 1.

Таблица 1. Действия, необходимые для осуществления этапа формализации ситуации, представленной на естественном языке, в работах разных исследователей

\begin{tabular}{|c|c|}
\hline Действие & Исследователь, предлагающий действие \\
\hline $\begin{array}{l}\text { Анализ условия задачи с целью уточнения смысла входя- } \\
\text { щих в него понятий }\end{array}$ & А. В. Бобровская, М. В. Егупова, В. А. Стукалов \\
\hline $\begin{array}{l}\text { Упрощение формулировки задачи с целью ее последующего } \\
\text { математического анализа. Включает в себя простые дей- } \\
\text { ствия: выделение объектов окружающей действительности, } \\
\text { которые могут быть описаны средствами школьного курса } \\
\text { математики, и выделение существенных свойств описывае- } \\
\text { мого процесса и отбрасывание несущественных }\end{array}$ & $\begin{array}{l}\text { В. С. Былков (четко не выделяет, сформулировал сложное } \\
\text { действие «структурный анализ объекта», которое включает } \\
\text { в себя действие из столбца слева), М. В. Егупова (предложила } \\
\text { только выделение объектов), И. М. Шапиро, А. В. Бобровская } \\
\text { (предлагают выделение существенных свойств и отбрасыва- } \\
\text { ние несущественных), Т. В. Малкова, В. М. Монахов, PISA }\end{array}$ \\
\hline $\begin{array}{l}\text { Определение ограничений, предположений и упрощений, } \\
\text { лежащих в основе любого математического моделирования }\end{array}$ & $\begin{array}{l}\text { В. С. Былков (четко не выделяет, сформулировал сложное } \\
\text { действие «структурный анализ объекта», которое включает } \\
\text { в себя действие из столбца слева), В. А. Стукалов, И. М. Ша- } \\
\text { пиро, PISA }\end{array}$ \\
\hline $\begin{array}{l}\text { Распознавание аспектов задачи, которые соотносятся } \\
\text { со знакомыми математическими понятиями, фактами } \\
\text { или процедурами }\end{array}$ & В. А. Стукалов, PISA \\
\hline $\begin{array}{l}\text { Распознавание математической структуры, включая зако- } \\
\text { номерности, отношения }\end{array}$ & Т. В. Малкова, В. М. Монахов, В. А. Стукалов, PISA \\
\hline Определение переменных & $\begin{array}{l}\text { А. В. Бобровская, В. А. Стукалов, Т. В. Малкова, В. М. Монахов, } \\
\text { PISA }\end{array}$ \\
\hline $\begin{array}{l}\text { Переформулирование задачи в соответствии с математи- } \\
\text { ческими понятиями и соответствующими допущениями. } \\
\text { Объяснение взаимосвязи между формулировкой содержа- } \\
\text { тельной задачи и математическим языком. }\end{array}$ & PISA \\
\hline
\end{tabular}




\begin{tabular}{|l|l|}
\hline \multicolumn{1}{|c|}{ Действие } & \multicolumn{1}{|c|}{ Исследователь, предлагающий действие } \\
\hline $\begin{array}{l}\text { Выбор и использование наиболее эффективной компью- } \\
\text { терной программы для изображения математических от- } \\
\text { ношений, присущих контекстной проблеме }\end{array}$ & \\
\hline $\begin{array}{l}\text { Замена содержательных понятий (объекты и отношения) } \\
\text { их формально-математическими эквивалентами }\end{array}$ & $\begin{array}{l}\text { А. В. Бобровская, М. В. Егупова, В. С. Былков, В. А. Стукалов, } \\
\text { T. В. Малкова, В. М. Монахов, РISA }\end{array}$ \\
\hline $\begin{array}{l}\text { Формулирование содержательной задачи на математи- } \\
\text { ческом языке }\end{array}$ & А. В. Бобровская, В. С. Былков, В. А. Стукалов, PISA \\
\hline $\begin{array}{l}\text { Установление соответствия между содержательной и ма- } \\
\text { тематической моделью объекта в зависимости от предъяв- } \\
\text { ленных условий }\end{array}$ & М. В. Егупова, PISA \\
\hline $\begin{array}{l}\text { Соотнесение реальных объектов различной природы с од- } \\
\text { ной математической моделью. Описание реального объек- } \\
\text { та несколькими математическими моделями }\end{array}$ & М. В. Егупова \\
\hline $\begin{array}{l}\text { Создание пошаговых инструкций по решению проблем, } \\
\text { в том числе и на языке программирования }\end{array}$ & Т. В. Малкова, В. М. Монахов, РISA \\
\hline
\end{tabular}

Анализируя отечественные исследования, связанные с действиями, необходимыми для осуществления этапа интерпретации полученных результатов, мы обнаружили небольшое количество работ, посвященных данной проблеме. И. М. Шапиро (1990) говорит о необходимости владения методами проверки решения, распространения найденного решения на решение других практических задач, оценки итоговой степени точности полученных результатов и выяснения ее влияния на корректность решения задачи. М. В. Егупова (2014) предлагает рассматривать только два действия: анализ использованных математических методов решения с точки зрения их рациональности для исследования реального объекта и интерпретацию результата исследования математической модели с требуемой погрешностью.

Однако наиболее полный список действий, необходимых для проведения этапа интерпретации полученных результатов, был предложен в исследовании PISA (PISA 2021..., 2018). Разделяя позицию разработчиков данного исследования, положим предлагаемый ими список в основу определения перечня действий, необходимых для осуществления этапа интерпретации полученных результатов (Список 1).

Список 1. Перечень действий, необходимых для интерпретации полученных результатов

1) интерпретировать информацию, представленную в графической форме и/или диаграммах;

2) оценить математический результат с точки зрения контекста и объяснить, почему математический результат или заключение имеет или не имеет смысла, учитывая контекст проблемы;

3) интерпретировать (переводить) математический результат обратно в контекст реального мира;

4) оценить обоснованность математического решения в контексте реальной проблемы;

5) на основе понимания о том, как реальный мир влияет на результаты и расчеты, сделать контекстные суждения о применении и корректировке результатов;

6) критиковать и определять границы модели, используемой для решения проблемы;

7) использовать математическое мышление, чтобы делать прогнозы, представлять доказательства для аргументов, проверять и сравнивать предложенные решения.

Покажем теперь на примерах нескольких действий, необходимых для осуществления этапа формализации ситуации, представленной на естественном языке, что между отобранными нами действиями, необходимыми для построения математической модели в ходе решения практико-ориентированных задач, и умениями из видов грамотностей, предложенными А. Б. Воронцовым (2013), существует тесная взаимосвязь. Для подтверждения этого тезиса используем известную проблему, которую еще в древности решил греческий математик Эратосфен: найти математический способ, позволяющий измерить радиус Земли, если в распоряжении имеется скафис.

Первая трудность, с которой столкнется ученик при знакомстве с формулировкой проблемы поиска радиуса Земли - с новым термином «скафис». Для того чтобы получить возможность построить математическую модель, понадобится выполнить анализ условия задачи с целью уточнения смысла нематематических понятий и отношений, входящих в условие задачи. Организуя на уроке деятельность, направленную на преодоление данной трудности, учителю необходимо уточнить формулировку задачи, спланировать поиск информации, выбор способа получения информации (справочная литература, Интернет) и даже формулирование поискового запроса в случае обращения к поисковым системам Интернета, интернет-сайтам. Поскольку в изначальной формулировке содержатся незнакомые для учащихся термины, то работа над выяснением смысла этих терминов также способствует нахождению и освоению новых знаний в ходе работы над задачей.

Описание проблемы поиска радиуса Земли не дает информации о необходимых математических фактах, с помощью которых удастся решить задачу. Поэтому чтобы получить возможность исследовать данную проблему средствами математики, потребуются такие действия, как упрощение действующей формулировки задачи и выявление ограничений, предположений, полученных из контекста. Например, для характеристики понятия «Земля», имеющегося в условии задачи, потребуется указать форму, размер, для дальнейших рассуждений можно предположить, что Земля имеет форму идеального шара, что в действительности не совсем так. Поэтому работа по освоению названных действий направлена на анализ информации об объекте, выделение существенной информации, которая может пригодиться для решения поставленной задачи, а также для отсеивания лишних данных. 
Аналогичные рассуждения относительно других выделенных действий на этапе формализации ситуации, представленной на естественном языке, и интерпретации полученных результатов могут быть проведены в процессе анализа большого количества практико-ориентированных ситуаций.

Таким образом, рассмотренный нами выше пример практико-ориентированной ситуации показал, что, во-первых, можно установить, что все выполняемые действия по формализации конкретной ситуации и интерпретации полученного результата связаны с коммуникативными, учебными и информационными умениями, определяющими функциональную грамотность учащихся. Во-вторых, освоенные учителем выделенные действия определяют необходимое условие для подготовки учащихся к работе с практико-ориентированными задачами.

\section{Заключение}

Результаты проведенного нами исследования показали, что в настоящее время под функциональной грамотностью понимается способность личности использовать все постоянно приобретаемые в течение жизни знания, умения и навыки для решения максимально широкого диапазона жизненных задач в различных сферах человеческой деятельности, общения и социальных отношений. В рамках международного исследования PISA выделяются следующие ее виды: читательская, математическая, естественнонаучная, финансовая грамотности, глобальные компетенции. Для характеристики функциональной грамотности, в частности каждого из ее видов, помимо предметных компонентов коллектив ИСРО РАО выделяет еще интегративные. В качестве данных компонентов А. Б. Воронцов предлагает рассматривать учебные, коммуникативные и информационные умения.

Изучение вопроса о состоянии подготовки российских учащихся к формированию математической грамотности как одного из видов функциональной грамотности позволило выявить существующую проблему в реализации практического компонента математической грамотности, отметить недостаточную проработанность методических аспектов, связанных с формированием у учащихся основной школы умений строить математическую модель и интерпретировать полученные результаты в ходе решения практико-ориентированных задач.

Благодаря анализу инструментария международного исследования PISA, а также работ отечественных исследователей удалось выделить специфические действия (Таблица 1, Список 1) на этапах формализации ситуации, представленной на естественном языке, и интерпретации полученных результатов в процессе решения практико-ориентированных задач. Кроме того, в исследовании было показано, что между отобранными нами действиями по построению математической модели и интерпретации полученного результата можно установить связь с коммуникативными, учебными и информационными умениями. Но чтобы организовать обучение, направленное на формирование математической грамотности, соответствующую методическую подготовку должен пройти будущий учитель математики. В рамках такой подготовки будущему учителю предстоит не только самому научиться выполнять все действия, связанные с этапом формализации ситуации, представленной на естественном языке, и интерпретации полученного результата в процессе решения практикоориентированных задач, но и освоить методику, направленную на освоение школьниками содержания этих этапов. Поэтому перспективы дальнейшего исследования могут касаться построения методики обучения будущего учителя математики формированию у учащихся основной школы математической грамотности.

\section{Источники | References}

1. Алексеева Е. Е. Формирование познавательных умений учащихся 7-9 классов при обучении составлению задач в курсе геометрии: дисс. ... к. пед. н. М., 2017.

2. Беребердина С. П. Обогащение регуляторного опыта учащихся 7-9 классов в обучении алгебре: дисс. ... к. пед. н. М., 2018.

3. Бобровская А. В. Обучение методу математического моделирования средствами курса геометрии педагогического института: дисс. ... к. пед. н. СПб., 1996.

4. Боженкова Л. И. Методика формирования универсальных учебных действий при обучении геометрии: метод. пособие. Изд-е 4-е, электрон. М.: Лаборатория знаний, 2020.

5. Боженкова Л. И. Методика формирования УУд в обучении алгебре: монография. Изд-е 2-е. М.: Лаборатория знаний, 2017.

6. Былков В. С. Формирование понятия о математическом моделировании средствами курса алгебры и начал анализа 9 и 10 классов: дисс. ... к. пед. н. М., 1986.

7. Виноградова Н. Ф., Кочурова Е. Э., Кузнецова М. И. Функциональная грамотность младшего школьника: книга для учителя / под ред. Н. Ф. Виноградовой. М.: Российский учебник; Вентана-Граф, 2018.

8. Воронцов А. Б. Метапредметные образовательные умения. 2013. URL: https://eurekanext.livejournal.com/ 188095.html

9. Дидактическое сопровождение формирования функциональной грамотности школьников в современных условиях. Проект № 27.7948.2017/БЧ / рук. Т. С. Назарова. 2017. URL: https://www.instrao.ru/index.php/contentpage/271-didakticheskoe-soprovozhdenie-formirovaniya-funkcionalnoy-gramotnosti-shkolnikov-v-sovremennyhusloviyah 
10. Егупова М. В. Практико-ориентированное обучение математике в школе как предмет методической подготовки учителя: монография. М., 2014.

11. Иванова Т. А. Теоретические основы гуманитаризации общего математического образования: дисс. ... д. пед. н. M., 1998.

12. Иванова Т. А. Теория и технология обучения математике в средней школе: учеб. пособие для студентов математических специальностей педагогических вузов / под ред. Т. А. Ивановой. Изд-е 2-е, испр. и доп. Н. Новгород: НГПУ, 2009.

13. Иванова Т. А., Симонова О. В. Структура математической грамотности школьников в контексте формирования их функциональной грамотности // Вестник Вятского государственного университета. 2009 . № 1.

14. Ковалева Г. С., Красновский Э. А., Краснокутская Л. П., Краснянская К. А. Результаты международного сравнительного исследования PISA в России // Вопросы образования. 2004. № 1.

15. Краткие результаты исследования PISA-2018. 2019. URL: http://centeroko.ru/download/Report_PISA2018kr.zip

16. Малкова Т. В., Монахов В. М. Математическое моделирование - необходимый компонент современной подготовки школьника // Математика в школе. 1984. № 3.

17. Образовательная система «Школа 2100». Педагогика здравого смысла: сб. мат. / под науч. ред. А. А. Леонтьева. М.: Баласс, 2003.

18. Подлипский О. К. Функциональная грамотность как направление развития математического образования в школе // Мир науки, культуры, образования. 2020. № 6 (85).

19. Рослова Л. О., Карамова И. И. Готовность учителя к формированию математической грамотности: результаты опроса // Математика. 2020. № 2.

20. Саранцев Г. И. Методика обучения математике в средней школе: учеб. пособие для студентов мат. спец. пед. вузов и ун-тов. М.: Просвещение, 2002.

21. Стукалов В. А. Использование представлений о математическом моделировании в обучении математике: автореф. дисс. ... к. пед. н. М., 1975.

22. Теплов Б. М. Способности и одаренность // Вестник Московского университета. Серия 20 «Педагогическое образование». 2014. № 4 .

23. Шапиро И. М. Использование задач с практическим содержанием в преподавании математики. М.: Просвещение, 1990.

24. OECD Governing Board. PISA 2021 Mathematics Framework (First Draft). Stockholm, 2018.

25. PISA 2018 Assessment and Analytical Framework. P.: OECD Publishing, 2019.

26. PISA 2021 Mathematics Framework (Draft). 2018. URL: https://www.oecd.org/pisa/sitedocument/PISA-2021mathematics-framework.pdf

\section{Информация об авторах | Author information}

RU Бычков Александр Владиславович ${ }^{1}$

${ }^{1}$ Нижегородский государственный педагогический университет имени Козымы Минина (Мининский университет)

EN Bychkov Alexander Vladislavovich ${ }^{1}$

${ }^{1}$ Minin Nizhny Novgorod State Pedagogical University (Minin University)

${ }^{1}$ vsdq@mail.ru

\section{Информация о статье | About this article}

Дата поступления рукописи (received): 02.12.2021; опубликовано (published): 28.12.2021.

Ключевые слова (keywords): будущий учитель математики; математическая грамотность; учащиеся; основная школа; метод математического моделирования; future mathematics teacher; mathematical literacy; students; primary school; mathematical model approach. 